\title{
Locating of Rural Health Centers Equipped with Telehealth using GIS: A Case Study on Khorramabad City, Iran
}

\section{Safdari Reza', Ghazisaeedi Marjan', Sheikhtaheri Abbas², Saremian Marzieh ${ }^{3 *}$}

'School Allied Medical Sciences, Tehran University of Medical Sciences, Tehran, Iran.

${ }^{2}$ School of Health Management and Information Sciences, Iran University of Medical Sciences, Tehran, Iran

${ }^{3}$ School Allied Medical Sciences, Lorestan University of Medical Sciences, Khorramabad, Iran.

Study Area: Khorramabad city, Lorestan Province, Iran

Coordinates: $32.56^{\circ}$ to $33.51^{\circ} \mathrm{N} ; 47.41^{\circ}$ to $48.57^{\circ} \mathrm{E}$

\section{Abstract}

Residents of the rural and remote area always having limitations on accessing properly required service providers. In such condition, the establishment of rural health centers equipped with telehealth, and also the use of GIS for optimal site selection to the centers, would play an important role in facilitating the achievement of quality health services in desired time factor. This study intended to find the optimal sites for building the Rural Health Centers Equipped with remote health facilities in, Khorramabad City, using GIS. During the pilot study, we identified few effective locating criteria and sub-criteria for rural health centers equipped with telehealth, the priorities was also determined in that descriptive study. Further, we prepared a special layer for each criterion on the site selection, and by integrating such layers based on specified rules and patterns, about the spatial analysis , (like distance and density analysis) were done. For such methods, we used Arc Map, Arc Catalog and Arc toolbox environments of Arc GIS (version 9.3). Finally, a map was prepared that indicated the possibility of appropriateness for establishing the centers in the study area. Considering a large number of areas, the research team selected the areas which were the appropriate location for build rural health centers which could be equipped with Telehealth.

improved access to services, improved quality of clinical services with reduced expense and inconvenience (Moffatt \& Eley, 2010).

Facility location is a critical factor in the strategic planning of healthcare programs (Afshari \& Peng, 2014). Health care policy makers have long been involved with questions of location-deciding, i.e. where to locate new service resources, which existing facilities would be close, and how best to improve service locations (Cromley \& McLafferty, 2012). Among various tools for solving spatial locational problems, the capability of Geographical Information System (GIS) in spatial planning and management has been highly acknowledged (Njoku \& Akpan, 2014). GIS includes tools that capture, store, analyze, and manage data linked to geographic locations. GIS may also serve as a tool to aid decision makers in strategizing clinic placement and managing the forthcoming demand on healthcare resources (Taylor et al., 2012). studies have reported the benef its of telehealth for areas, such as better access to health care specialists,

*Corresponding Author: marziehsaremian@yahoo.com 
Various studies have utilized geographic information systems to settle hospital or health care-related problems. Perry \& Gesler (200o) applied GIS system to find out the residents' access to the health care centers in a distant area of Andean Bolivia. Bramanti et al., (2010) used GIS to analyze the optimal location of territorial telemedicine spots in correspondence of general practitioner clinics linked to the telemedicine services or specialized clinics. Their work also helped to involve general practitioners in the management of patients (Bramanti et al., 2010).

Fortunately, the use of such technologies, in many countries brings the medical care closer to patients. This ease of access, in countries having less-developed transportation network, such as Iran where its civilization distribution in mountainous and impassable areas would certainly help the patients in early diagnosis of disease, access to medical expertise centers adopting the tactics of the right treatment, reducing the time and cost (Behbahani \& Maridani, 2013). Residents in rural and remote areas like Khorramabad have access to a small range of service providers and typically have to travel long distances to urban centers in order to receive specialized care. For patients and their respective family members, such travel puts a great financial and emotional burden (Mitton et al., 2011). Thus the issues regarding the access to health services, especially in mountainous and impassable areas, should be considered a major concern for policy makers. In such condition, the establishment of rural health centers equipped with telehealth services and technologies in the right locations would play an important role in improving access time bound quality health services.

As per Statistical Yearbook of Lorestan, (2012) by the year 2011, In Khorramabad, there were only 13 hospitals, maternity, and nursing homes. Furthermore, in the villages surrounding the city, there are 13 rural health centers Thus, this study was aimed to determine optimal sites for building rural health centers that can be equipped with telehealth services in one of the mountainous cities of Iran, Khorramabad City, by using GIS based on different criteria. The Analytical Hierarchy Process (AHP) is used to identify the weighting of each criterion for weight setting.

\section{Materials and methods:}

Study Area: The study area was the few villages associated with the city of Khorramabad in Lorestan Province of Iran covering approximately $4935 \mathrm{~km} 2$. The city of Khorramabad is composed of four districts, four towns, 17 rural districts and 609 villages, with the total human population of about 132034 in rural areas (Office of Statistics and Information and GIS of Lorestan, 2012, Statistical Yearbook of Lorestan).

Khorramabad is situated in the Zagros Mountains. Lorestan has many permanent river streams, many forests, grasslands and agrarian lands surrounding it that is why the base of this province's economy is agricultural and livestock.

While pilot study, we had already identif ied effective locating criteria and sub-criteria for rural health centers equipped with telehealth using litereture review, also the priorities had determined with AHP methode in the descriptive cross sectional study. (Safdari et al., 2015). Further, a special layer for each factor affecting on the site selection, and by integrating these layers based on specif ied rules and ratterns, analysis were also done.

\section{Preparation layers affecting on the site selection:}

The data used in this piece of work are mainly of two types: spatial and descriptive data. The spatial data in the form of required maps according to the determined layer in the first phase of the study, were received from the governorship of Lorestan province and health deputy of Lorestan University of Medical Sciences. These maps included villages, roads, population density, rivers, hospitals, land use, slope and elevation point's map and the boundary of Khorramabad city and surrounding villages, as the study area. At first, the maps, using GIS and application of Geo referencing and Digitizing functions, were prepared. Furthermore following statistics, databases related to geographical features, were completed. Further, for all criteria and sub-criteria, separated layers were defined. For such actions, we used Arc Map, Arc Catalog and Arc toolbox environments of Arc GIS (version 9.3).

\section{Weighing to the layers:}

As per the required ratio (weight),in the Arc Map, layers obtained from the sub-criteria were combined. Thus for all criteria and sub-criteria, layers were obtained which were the same in the unit (the appropriateness degree). In each map, the weight of each location was shown according to criteria and sub-criteria.

\section{Combination of the produced Layer:}

According to the weight of criteria and subcriteria, the layers that obtained from the Previous stage (reclass layers) were combined to produce a raster that $\mathrm{s} \mathrm{h}$ o w e d t h e appropriateness degree of Study Area to build rural health centers equipped with Telehealth. The stages of locating are shown in Fig.- 1.
Preparation of digitized maps and database according to the provided statistics

Creating effective layers in locating based on the criteria and sub-criteria 1)

The combination of layers based on the weight of each of them

Providing the final locating map for the establishment of rural health centres equipped with telehealth

Figure-1: locating various stages of rural health centers equipped with telehealth 


\section{Results :}

The effective criteria and sub-criteria in locating rural health centers equipped with telehealth and their priorities are presented in Table-1. As per the Table 1, among the criteria and sub-criteria, "population," "accessibility" and " distance from main thoroughfares" has been placed in the highest priority whereas the "Distance from military areas" in the lowest priority.The purpose of locating was to find out the best places for the establishment of rural health centers equipped with telehealth. The first layers ( 13 layers) of the study area included boundary of the study area, slaughterhouses, industrial centers, military centers, hospitals, elevation points, roads, rivers, land use, mountains, population density, bandwidth and network type maps. The Fig.- 2 \& 3 are examples of these layers.

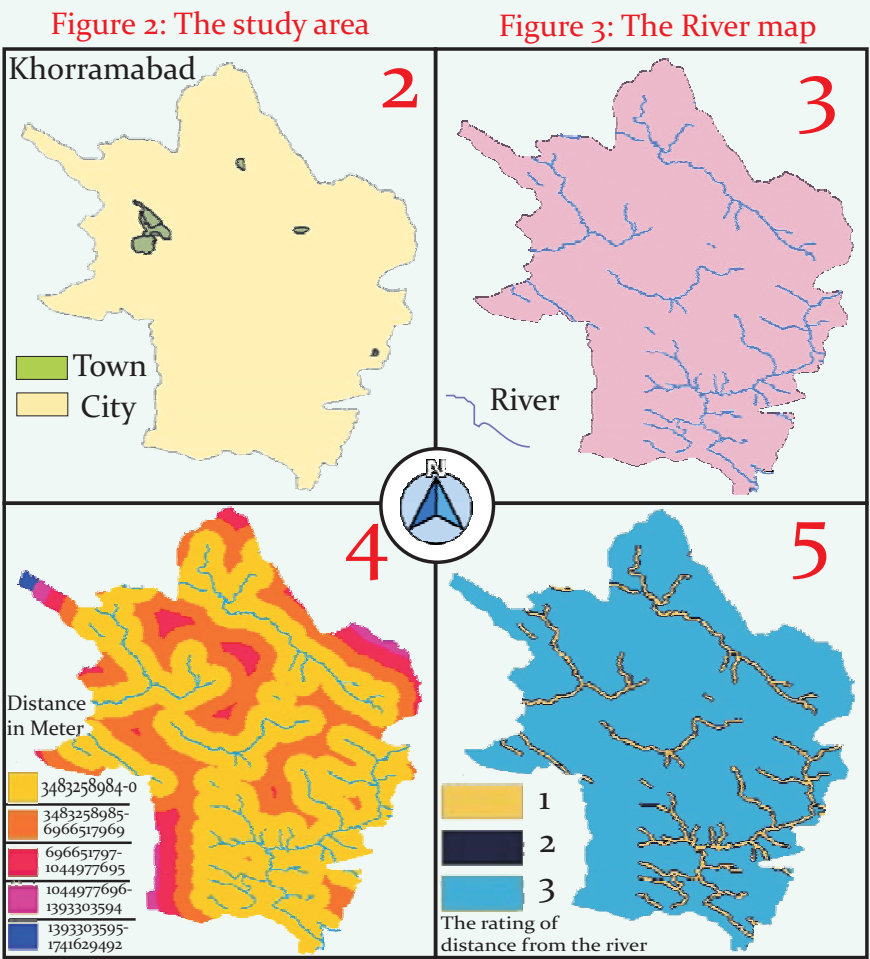

Figure-4: Distance from the rivers' raster

Figure-5: Reclassification of map as per the distance from the rivers

The Fig.- 4 shows the distances from the rivers in the studied area. As shown in the figure, if the distance from the rivers is far, the area is more suitable for the establishment of rural health centers. The reclassified layer of the "distance from river" layer is shown in figure 6. In the next stage, new raster based on the weight of the criteria and sub-criteria were produced through the mathematical overlay. This raster showed the appropriateness degree of different parts of the study area to locating rural health centers equipped with telehealth. After a phase of reclassif ication, the study area's map was obtained according to appropriateness percent (Fig.-6). In

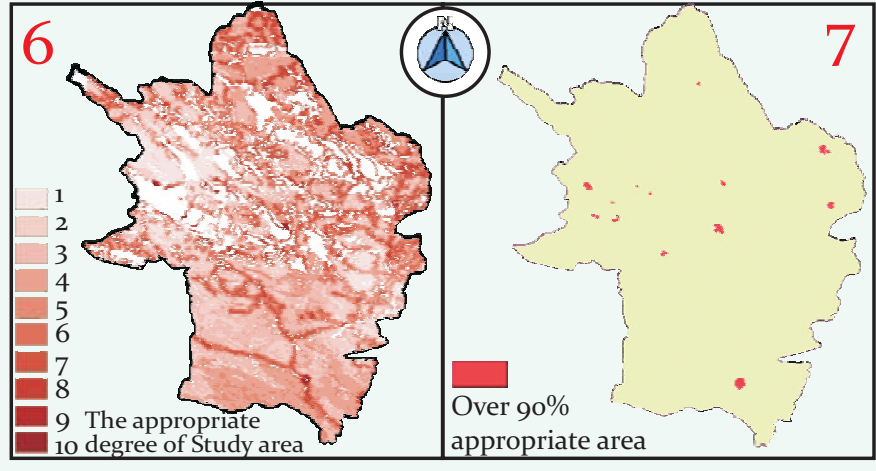

Figure-6: Appropriateness level Figure-7: 90 \& 100\% appropriate of Study Area to build rural area for build rural health healthcenters equipped with centers equipped with telehealth

telehealth.

Table 1-The effective criteria and sub-criteria

\begin{tabular}{|c|c|c|c|c|}
\hline Criteria & weight & sub-criteria & weight & $\begin{array}{r}\text { Final } \\
\text { weight }\end{array}$ \\
\hline \multirow{4}{*}{$\begin{array}{l}\text { Boundary \& } \\
\text { distance } \\
\text { from non- } \\
\text { compliances }\end{array}$} & \multirow[t]{4}{*}{0.060} & $\begin{array}{l}\text { Distance from } \\
\text { industrial centers }\end{array}$ & 0.313 & 0.19 \\
\hline & & $\begin{array}{l}\text { Distance from } \\
\text { slaughter houses }\end{array}$ & 0.212 & 0.313 \\
\hline & & $\begin{array}{l}\text { Distance from } \\
\text { militaryareas }\end{array}$ & 0.169 & 0.010 \\
\hline & & $\begin{array}{l}\text { Distance from } \\
\text { the rivers }\end{array}$ & 0.306 & 0.018 \\
\hline \multirow[t]{2}{*}{$\begin{array}{l}\text { Transportation } \\
\text { networks }\end{array}$} & \multirow[t]{2}{*}{0.249} & $\begin{array}{l}\text { Distance from other } \\
\text { health centers }\end{array}$ & 0.299 & 0.074 \\
\hline & & $\begin{array}{l}\text { Distance from main } \\
\text { thoroughfares }\end{array}$ & & \\
\hline Population & 0.259 & - & - & 0.259 \\
\hline Land use & 0.050 & $=$ & - & 0.050 \\
\hline Accessibility & 0.225 & $\overline{-}$ & - & 0.225 \\
\hline Topography & 0.077 & Slope & 0.680 & 0.053 \\
\hline characteristics & & Height & 0.320 & 0.025 \\
\hline Technical & 0.246 & Bandwidth & 0.745 & 0.060 \\
\hline factors & & Type of network & 0.246 & 0.019 \\
\hline
\end{tabular}

the last stage, the final raster converted to a polygon so that the scope of any region determined.

While considering the large areas, the research team decided to choices such areas which were having almost 90 percent appropriateness level and further areas as the most suitable location for build rural health centers equipped with Telehealth (Fig.-7).

We accessed the appropriateness percent of areas are as follows: $10 \%$ appropriate $=131 ; 20 \%$ appropriate $=698$; $30 \%$ appropriate $=1240 ; 40 \%$ appropriate $=1681$; $50 \%$ appropriate $=2045 ; 60 \%$ appropriate $=1626$; $70 \%$ appropriate $=840 ; 80 \%$ appropriate $=238$; $90 \%$ appropriate $=36 ; 100 \%$ appropriate $=9$

\section{Discussion:}

As an output of our study regarding the propsed location for rural health centers equipped with Telehealth in Khorramabad city, a map has been evolved that reveal the percent of appropriateness for establish the centers in the 
studied area. Further, the areas that have been identified as appropriate with the high possiblities (according to the team study decision, the 90 percent appropriate and further areas) were visited and from the aspect of land area, public, private or endowed had been evaluated to identify the establishment area of rural health centers equipped with Telehealth. Earlier a combined health centers map with the population distribution map together were presented and through which the authors determined the optimal locations for the health centers (Ismaila and Usul 2013). In our study, for the first time, the best place for establish of rural health centers equipped with telehealth technology have been introduced. But the distribution of existing health centers has not been compared with the optimal locations.

Bramanti et al. (2010) reported that the patient couldn't benefited from telemedicine only due to the lack of accessing a high-speed internet and is such condition GIS would be the best alternative. They identified some of the areas as potential regional station to provide telemedicine services. Such area palaces, where people connect to telemedicine service's providers to their clinics, would mainly the GP clinics (Bramanti, 2010). As have included telemedicine services with rural health centers to provide health services. Khakpur et al (2012) identified medical centers in Neyshabur based on several criteria where the final map was divided the study area into the regions with three different priorities (Weak priority, moderate priority, strong priority). According to the result of the studies, locating of health centers using GIS and based on several criteria, lead to equitable distribution and easy access to these centers. Moreover, through the use of GIS capabilities for locating health centers can investigate the distribution of existing centers and planning for future in order to rectify possible inequalities in achievement of quality health services. Additionally, the result of our study shows that the use of GIS can be a powerful tool in determining the best location for establish of rural health centers based on several criteria.

In other words, several factors are involved in locating of rural health centers, while manual investigation of all of them is quite impossible. In addition, considering such factors and the impact of each of them in locating of rural health centers, lead to equitable distribution of such centers. It saves time and energy, ease of timely access to quality care and finally promotes the health in the country.

Therefore, the use of technology such as GIS in locating of rural health centers, can improve the quality of planners' work, as well as enhance the quality of people life, particularly people those living in rural and remote areas that are deprived of many resources, especially in the health field. In addition, the use of other new technologies such as telehealth leads to easy and timely access to quality health services, and it is very important in providing service to deprived areas.

\section{Acknowledgements:}

We would like to thank all those who contributed to this research in any way. The study results from the thesis approved by the Tehran University of Medical Sciences ( 57 / F / 3/280). We have no conflict of interest regarding the publication of this paper.

\section{References:}

Afshari, H. \& Peng, Q (2014): Challenges and Solutions for Location of Healthcare Facilities. Ind. Eng. Manage., 3(127): DOI: 10.4172/2169-0316.100012.

Alharthi, M.S. (2012): Telehealth practice in eight countries: New Zealand, Australia, the USA, Canada, UK, Malaysia, China and India. PhD Thesis, Massey University, Auckland

Behbahani, S. \& Maridani, M.K. (2013): Whatever we should know about telemedicine. MED E LAB Eng. Mag., 13(145):33-35.

Bramanti, A., Bonanno, L., Celona, A., Bertuccio, S.,Calisto, A., Lanzafame, P. \& Bramanti, P. (2010): GIS and spatial analysis for costs and services optimization in neurological telemedicine. Engineering in Medicine and Biology Society $(\mathrm{EMBC})$, Annual International Conference of the IEEE, IEEE.

Cromley, E.K. \& McLafferty, S. (2012): GIS and public health, Guilford Press.

Ismaila, A.B. \& Usul, N. (2013): A GIS-based Spatial Analysis of Health care Facilities in Yola, Nigeria. GEO-Processing 2013, The Fifth International Conference on Advanced Geographic Information Systems, Applications, and Services.

Khakpur, B., Khodabakhshi, Z. \& Ghuzlu, E.M. (2012): Site Selection for Medical Centers, Using GIS and Analytical Hierarchy Process (AHP), in Two Districts in Neyshabour City.J. Geog.Reg. Dev., 10(19):1-20.

Mitton, C.F. Dionne, F., Masucci, L., Wong, S. \& Law, S. (2011) Innovations in health service organization and delivery in northern rural and remote regions: a review of the literature. Int. J. Circumpolar. Health, $70(5): 460-472$

Moffatt, J.J. \& Eley, D.S. (2010): The reported benef its of telehealth for rural Australians. Aust. Health Rev., 34(3): 276-282.

Njoku, E.A. \& Akpan, P.E. (2014): Location Efficiency of Healthcare Facilities in Ikot Ekpene Local Government of Akwa-Ibom State: the Role of Geographical Information System (GIS). Int. Lett.Soc. Human. Sci. 4:22-30.

Perry, B. \& Gesler, W. (200o): Physical access to primary health care in Andean Bolivia. Soc. Sci. Med., 5o(9):1177-1188.

Safdari, R., Ghazisaeedi, M., Seikhtaheri, A. \& Saremian, M. (2015): Prioritizing the factors influencing places of rural health centers equipped with telehealth services using Analytical Hierarchy Process. L. Clin. Res. Paramed. Sci., 4(1): 24-33.

Taylor, D.M., Yeager, V.A. Ouimet, C. \& Menachemi, N. (2012): Using GIS for administrative decision-making in a local public health setting. Public Health Rep., 27(3):347-353

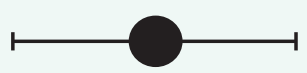

